\title{
Testicular expression of long non-coding RNAs is affected by curative GnRHa treatment of cryptorchidism
}

\author{
Faruk Hadziselimovic ${ }^{1 *}$, Gilvydas Verkauskas ${ }^{2}$, Beata Vincel ${ }^{3}$ and Michael B. Stadler ${ }^{4,5}$
}

\begin{abstract}
Background: Cryptorchidism is a frequent endocrinopathy in boys that has been associated with an increased risk of developing testicular cancer and infertility. The condition is curable by combined surgery and hormonal treatment during early pre-pubertal stages using gonadotropin releasing hormone agonist (GnRHa). However, whether the treatment also alters the expression of testicular long non-coding RNAs (IncRNAs) is unknown. To gain insight into the effect of GnRHa on testicular IncRNA levels, we re-analyzed an expression dataset generated from testicular biopsies obtained during orchidopexy for bilateral cryptorchidism.

Results: We identified EGFR-AS1, Linc-ROR, LINC00221, LINC00261, LINC00282, LINC00293, LINC00303, LINC00898, LINC00994, LINC01121, LINC01553, and MTOR-AS1 as potentially relevant for the stimulation of cell proliferation mediated by GnRHa based on their direct or indirect association with rapidly dividing cells in normal and pathological tissues. Surgery alone failed to alter the expression of these transcripts.

Conclusion: Given that IncRNAs can cooperate with chromatin-modifying enzymes to promote epigenetic regulation of genes, GnRHa treatment may act as a surrogate for mini-puberty by triggering the differentiation of Ad spermatogonia via IncRNA-mediated epigenetic effects. Our work provides additional molecular evidence that infertility and azoospermia in cryptorchidism, resulting from defective mini-puberty cannot be cured with successful orchidopexy alone.
\end{abstract}

Keywords: Spermatogenesis, Cryptorchidism, Male infertility, GnRHa, IncRNAs, Antisense IncRNAs, lincRNAs, Mitosis

\section{Résumé}

Contexte: La cryptorchidie est. une endocrinopathie fréquente chez les garçons. Elle est. associée à un risque élevé de cancer des testicules et d'infertilité. La cryptorchidie peut être soignée par une thérapie incluant une intervention chirurgicale et un traitement hormonal par l'agoniste de l'hormone GnRH. Alors que l'effet de la thérapie sur l'expression des ARNm a été analysé, ses conséquences pour la transcription des longs ARNs non codants (ARNInc) testiculaires restent inconnues. Afin de mieux comprendre les effets du GnRHa sur les concentrations cellulaires des ARNInc dans le testicule, nous avons analysé des données d'expression d'ARN par séquençage (ARN-Seq) générées en utilisant des biopsies testiculaires obtenues dans le cadre d'une orchidopexie pour cryptorchidie bilatérale.

(Continued on next page)

\footnotetext{
* Correspondence: liestal@kindermedizin-zentrum.ch

${ }^{1}$ Cryptorchidism Research Institute, Children's Day Care Center, 4410 Liestal,

Switzerland

Full list of author information is available at the end of the article
}

(c) The Author(s). 2019 Open Access This article is distributed under the terms of the Creative Commons Attribution 4.0 International License (http://creativecommons.org/licenses/by/4.0/), which permits unrestricted use, distribution, and reproduction in any medium, provided you give appropriate credit to the original author(s) and the source, provide a link to the Creative Commons license, and indicate if changes were made. The Creative Commons Public Domain Dedication waiver (http://creativecommons.org/publicdomain/zero/1.0/) applies to the data made available in this article, unless otherwise stated. 


\begin{abstract}
(Continued from previous page)
Résultats: Nous avons identifié les ARNInc EGFR-AS1, Linc-ROR, LINC00221, LINC00261, LINC00282, LINC00293, LINC00303, LINC00898, LINC00994, LINC01121, LINC01553, et MTOR-AS1 comme potentiellement pertinents pour la stimulation de la prolifération cellulaire induite par le GnRHa. Cette conclusion fait référence à leur association directe ou indirecte avec la croissance et division cellulaire mitotique rapide dans les tissus normaux et pathologiques. Nous constatons également que la chirurgie seule n'a pas d'effet détectable par ARN-Seq sur l'expression de ces ARNInc.

Conclusion: Étant donné que certains ARNInc coopèrent avec des enzymes ayant un effet sur la structure chromatinienne et la régulation épigénétique des gènes, le traitement par GnRHa pourrait substituer la mini-puberté en déclenchant la différenciation des spermatogonies Ad par un mécanisme épigénétiques qui dépendrait des ARNInc. Notre travail révèle des nouvelles pistes moléculaires soutenant l'hypothèse que l'infertilité et l'azoospermie associées avec la cryptorchidie sont la conséquence d'une anomalie de la mini-puberté. Cela explique pourquoi une thérapie efficace de cette pathologie ne nécessite pas seulement l'orchidopexie mais aussi un traitement hormonal.
\end{abstract}

Mots-clés: Spermatogénèse, cryptorchidie, GnRHa, ARN/nc, ARN/nc antisense, mitose

\section{Introduction}

Long non-coding RNAs (lncRNAs) have emerged as key regulators of gene expression in embryonic stem-cell (ESC) self-renewal and differentiation. In ESCs, lncRNAs are regulated at the genetic level by transcription factor binding to lncRNA gene promoters. A major function of lncRNAs is the regulation of specific gene expression at multiple steps, including the recruitment and expression of basal transcription machinery, post-transcriptional modifications, and epigenetics [1]. LncRNAs have also been proposed to play a targeting role by binding to certain methyltransferases and demethylases, and directing them to specific genomic locations. Depending on the biological context, certain methylation events are stably maintained (e.g., methylation involved in inheritance through mitosis of a silenced heterochromatin state), whereas others have to be amenable to change (e.g., when cells differentiate or respond to environmental cues) [2-5]. The so-called natural antisense transcripts (NATs) have been shown to regulate gene expression by affecting transcription and mRNA stability [2-5]. Almost $80 \%$ of the mammalian genome is transcribed, and many genomic loci produce RNAs from both sense and antisense DNA strands [6-8], though the functional importance of most of these transcripts is only poorly characterized.

We have previously demonstrated that the presence of type A dark (Ad) spermatogonia in the testis is a marker of low infertility risk (LIR), whereas low or absent levels (below a critical threshold) indicate high infertility risk (HIR) $[9,10]$. Treatment with a gonadotropin-releasing hormone agonist (GnRHa, buserelin) enables the Ad spermatogonia population to recover, significantly improving fertility in HIR patients [11]. GnRHa induces a broad transcriptional response, including genes encoding proteins involved in pituitary development, the hypothalamic-pituitary-gonadal axis, and testosterone synthesis [12]. Earlier work focused on proteincoding mRNAs; consequently, nothing is known about the expression of lncRNAs in the treatment of cryptorchidism.
We identified several hundred GnRHa-responsive lncRNAs, which were grouped into long intergenic non-coding RNAs (lincRNAs) and antisense (AS) lncRNAs. We selected candidates on the basis of their expression profiles and then prioritized them for roles in cell growth, differentiation, and disease based on a literature search in PubMed (www.ncbi. nlm.nih.gov/pubmed/). We also included in this search protein-coding genes located upstream or downstream lincRNAs and sense genes overlapping ASlncRNAs. In addition, we explored the RNA-RNA interaction data available in the RISE database (http://rise.life. tsinghua.edu.cn). Finally, we interpreted lncRNA expression signals in the context of protein/RNA profiling data published by the Human Protein Atlas (www.proteinatlas. org) and RNA-sequencing data from HIR/LIR patients [12]. We propose that certain hormone-responsive lncRNAs may play a role in establishing adult spermatogenesis during pre-pubertal stages of development by controlling testicular cell proliferation.

\section{Materials and methods}

Study population and biopsy sample collection

The samples used in this study have been described elsewhere [12-14]. A cryptorchid testis is defined as a testis localized outside of the scrotum and incapable of being brought into a stable scrotal position. Sixteen boys with isolated bilateral cryptorchidism who underwent orchidopexy were prospectively included in this study (Fig. 1). The patients had a median age of 18.5 months (range 8-59 months). During the first orchidopexy, biopsies of the ipsilateral testicle were obtained from all patients. Based on histological evaluation, biopsies were categorized into two groups, Ad- (or HIR) and $\mathrm{Ad}+$ (or LIR),. The Ad- group included biopsies with no Ad, and the Ad+ group included testes with Ad spermatogonia (Fig. 1). Cryptorchid boys in the Ad- 


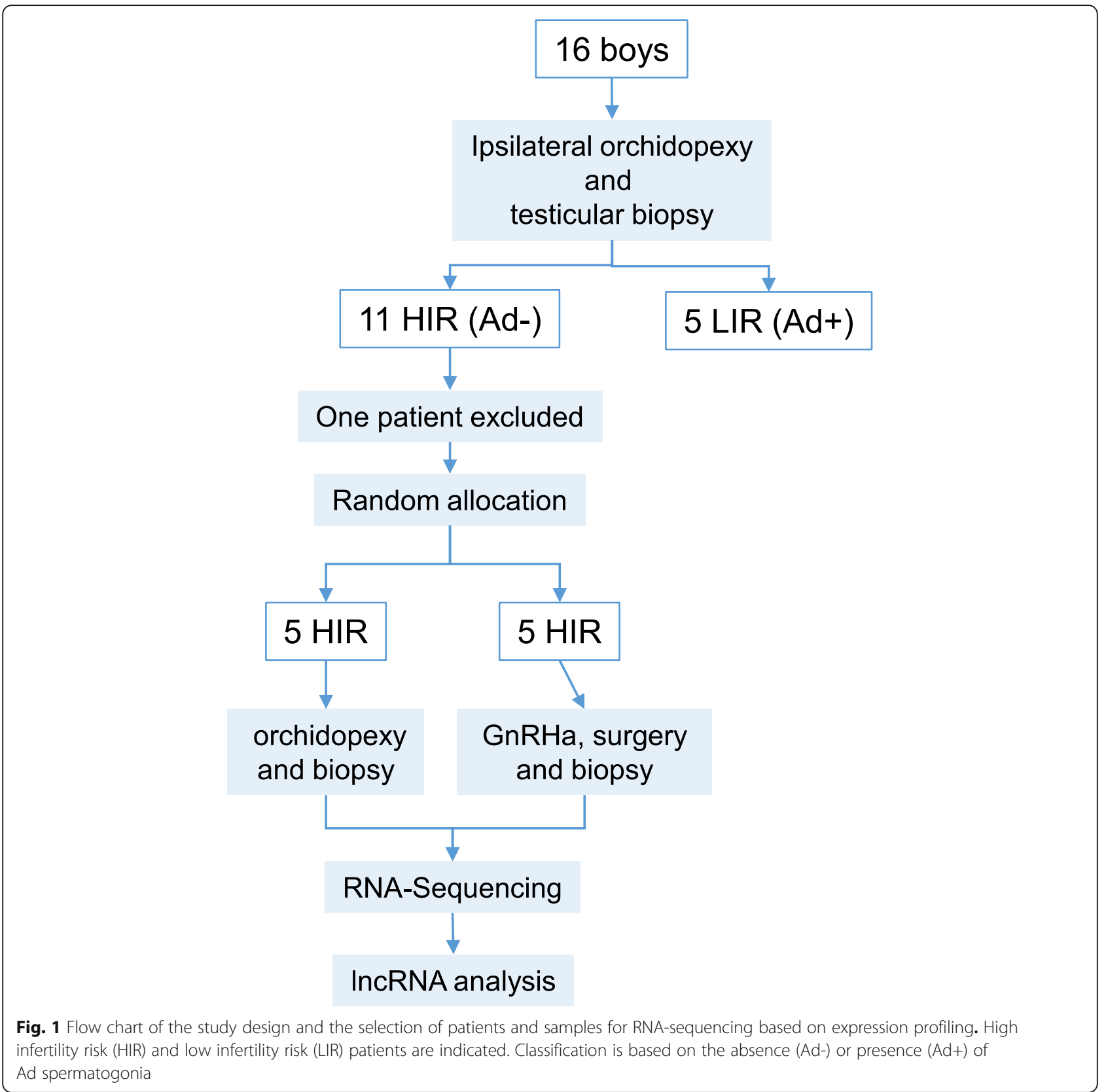

group had 8-times lower plasma LH levels $(0.11 \mathrm{IU} / \mathrm{L})$ than the $\mathrm{Ad}+$ group $(0.89 \mathrm{IU} / \mathrm{L}, p<0.009)$, indicating hypogonadotropic hypogonadism [13]. Five boys (Adgroup) were randomly included in each arm. One HIR patients was excluded (Fig. 1.) In the GnRHa-treated group, the median total germ cell count per tubule $(\mathrm{S} /$ $\mathrm{T})$ increased from 0.11 to $0.42(p=0.03$, paired-samples Wilcoxon test, one-tailed). In the surgery only group, the median S/T did not change and none of the testes had Ad spermatogonia. In contrast, in the GnRHa treated group, all testes completed the transition from gonocytes to Ad spermatogonia $(p=0.008$; Fisher test, 2-tailed) [14].

\section{RNA-sequencing data analysis}

The workflow from RNA isolation to purification, library preparation, sequencing, data analysis, and expression level analysis has been described in detail elsewhere [12]. Determination of differentially expressed genes, statistical analyses, and model design were carried out as described previously [12]. Genomic coordinates for known IncRNAs were obtained from the Bioconductor package TxDb.Hsapiens.UCSC.hg19.lincRNAsTranscripts (version 3.2.2). Only genes with at least one read per million, in at least two samples were included. $P$-values and fold-changes were calculated for the treatment factor, and differentially expressed genes were defined as those with a 
false discovery rate (FDR) of less than 0.05 . Raw data files are available at the Database of Genotypes and Phenotypes (dbGaP) under accession number phs001275.v1.p1. Expression signals are given in standard RKPM units. They are calculated as follows: the number of reads mapped to a gene sequence is divided by the length of the gene sequence over 1000 multiplied by the total number of mapped reads per sample over $1^{\prime} 000^{\prime} 000$.

\section{LncRNA data interpretation}

We analyzed lincRNA and AS-lncRNA expression in cryptorchid patients with HIR before and after GnRH treatment to identify all RNAs annotated as antisense (AS) transcripts, as well as all RNAs annotated as lincRNAs with $\log \mathrm{FC}>1.0$. In addition, we compared lincRNA and AS- IncRNA expression between the HIR and LIR groups of cryptorchid patients and analyzed those with lower expression in the HIR group. LincRNAs and AS- IncRNAs were prioritized based on RNA-RNA interactions, revealing the lncRNAs, AS- IncRNAs, or mRNAs encoding proteins involved in spermatogenesis or fertility, and important lncRNAs or mRNAs encoding proteins involved in cell division/growth, signaling pathways, and cancer. Furthermore, we included five lincRNA directly related to spermatogenesis that had a $\log \mathrm{FC}>1.0$. After the ASIncRNA candidates were identified, they were prioritized based on a PubMed literature search of themselves and their overlapping sense mRNA/protein, revealing roles in spermatogenesis, fertility, cell division/growth, signaling pathways, and cancer (www.ncbi.nlm.nih.gov/pubmed). The RNA annotation was verified using Ensembl (www. ensembl.org; release 97). The lincRNA/mRNA expression was interpreted using GermOnline (www.germonline.org; version 4.0), Human Protein Atlas (www.proteinatlas.org; version 18), and Genevestigator (www.genevestigator.com; version 7.3.1). Experimentally validated RNA-RNA interaction data were retrieved from RISE (http://rise.life.tsinghua.edu.cn; version 1.0).

\section{Results}

\section{Global effects on testicular IncRNA levels in response to} GnRHa treatment

First, we identified significantly differentially expressed IncRNAs in duplicate testicular biopsies from LIR and HIR patients who underwent surgical correction of undescended testis (Fig. 2, lanes 1-4).

Next, we compared samples obtained from HIR patients at the time of initial surgery (Fig. 2, lanes 5 and 6) and after six months of treatment with GnRHa (Fig. 2, lanes 7 and 8). The genes were ordered using an unsupervised clustering method (hierarchical clustering with complete linkage using Euclidean distances) and are shown in a false-color heatmap relative to the mean expression of each gene over all samples in Fig. 2. The results indicate that a large number of lncRNAs accumulate at low levels in the testes of boys with HIR compared to LIR, and that a substantial fraction of these transcripts is up-regulated by GnRHa treatment. In contrast, surgery alone had no significant impact on lncRNA expression. We explored the dataset using Volcano plots that display statistical significance (false discovery rate, FDR) against fold-change of expression signals allowing the selection of genes for which large and significant differences in expression levels were observed (Fig. 3).

We found that 627 and $38 \operatorname{lncRNAs}$ were expressed at lower and higher levels, respectively, in HIR versus LIR samples (Fig. 3a). We concluded that the vast majority of differentially expressed lncRNAs are detected at lower levels in HIR testes. Comparing HIR testes before and after GnRHa treatment, we found that 3074 lncRNAs were increased, whereas 53 were decreased (Fig. 3b). Thus, hormonal treatment induces a considerable number of lncRNAs. In the following section the novel lncRNAs were organized based on their known functions or roles that were attributed to their potential target genes.

\section{Certain testicular lincRNAs upregulated by $\mathrm{GnRHa}$ treatment are involved in stem cell renewal, signaling, and cell differentiation}

We also sought to gain insight into the potential roles that hormone-responsive RNAs might play by interpreting their genomic location, association with protein coding genes in sense/antisense pairs, and RNA-RNA interactions. We selected 11 of 77 lincRNAs and four of 46 AS-lncRNAs with $>2.0$-fold change after GnRHa treatment because their expression patterns lead us to hypothesize that they are important for the development of Ad spermatogonia (Table 1). In this section we focus on novel potential regulatory lincRNAs and we provide context information about their putative protein-coding target genes. This includes previously published expression data obtained with samples from HIR and LIR patients (fold change and FDR values) [12] and functional information relevant for germ cells growth and differentiation from the literature.

LINC01016 is a so-called hub RNA that binds many mRNAs (encoding epigenetic regulators and transcription factors) and lincRNAs (including XIST). This feature distinguishes a hub RNA from most other transcripts that interact with few, one or no other RNAs. LINC01016 is expressed in the same direction as MLN (Motilin) and is a transcriptional target of the estrogen receptor [15] (Table 1).

LINC01121 is expressed upstream of SIX2 and may influence its proximal promoter regions. SIX2 interacts with TCF7L2 and OSR1 in a canonical WNT signalingindependent pathway, preventing the transcription of 


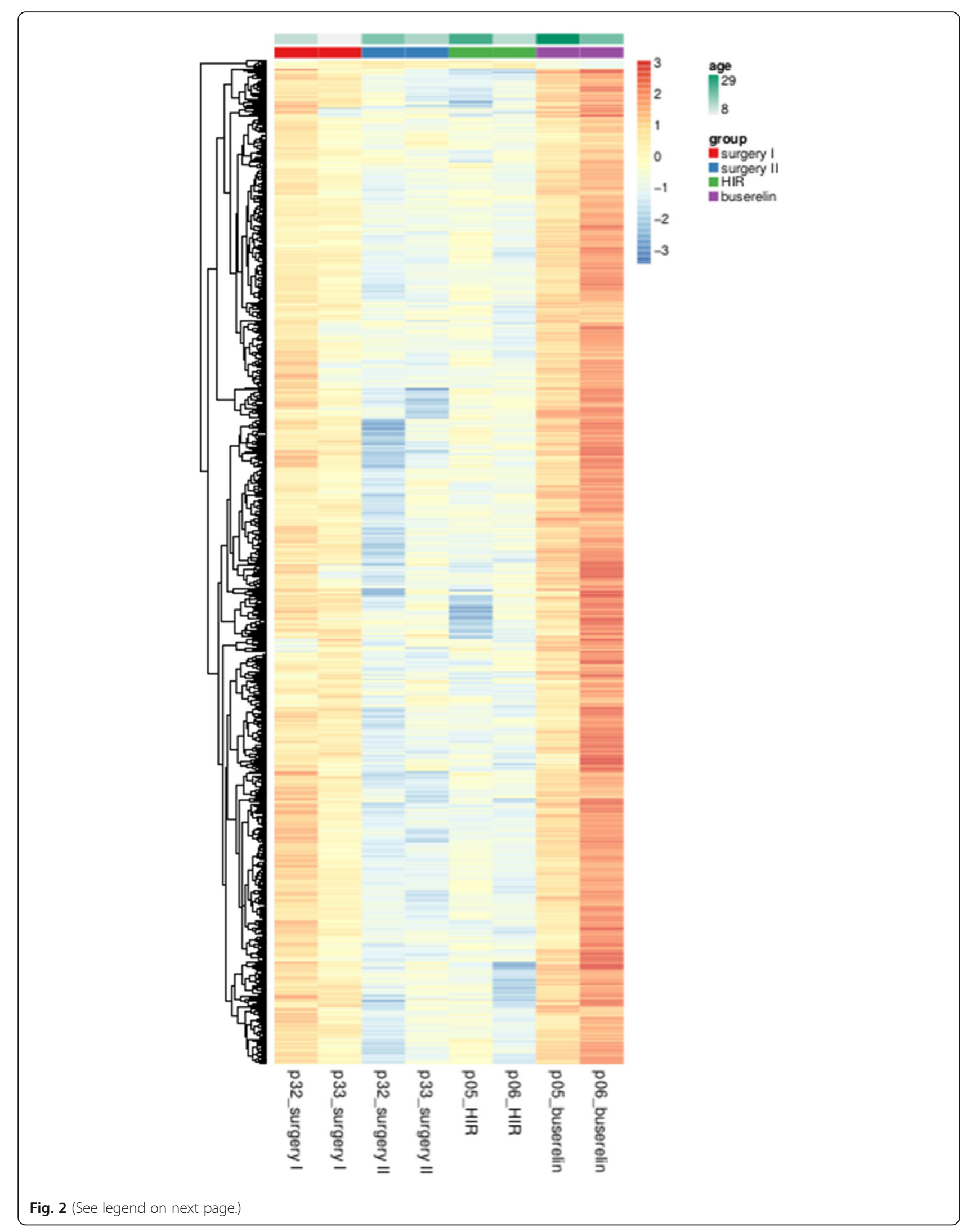


(See figure on previous page.)

Fig. 2 RNA-sequencing data for IncRNAs. A false color heatmap (red is high, blue is low) shows data from pairs of testes, analyzed. Horizontal bars at the top indicate patient categories and age. Four sample from two HIR patients (p32 and p33; biopsy number) having had surgery "only" treatment; line 1 and 2 during first surgery obtained from ipsilateral testis (I), line 3 and 4 show results from contralateral testis six months after first orchidopexy (II) Buserelin treated patients p5 and p6; line 5 an 6 before treatment and line 7 and 8 contralateral testis after hormonal treatment. Color scales for expression (red/blue) and age (green) are shown

differentiation genes in cap mesenchyme, such as WNT4 [16-18] (Table 1).

LINC00261 is expressed in the 3'regions of PAX1 and FOXA2, which encode transcription factors. It is also a hub lncRNA that binds mRNAs and lncRNAs, including HOTAIR, and is an epigenetically regulated tumor suppressor that is essential for activation of the DNA damage response [19]. FOXA2 is involved in androgen receptor regulation [19-21] and upregulated after $\mathrm{GnRHa}$ treatment $(\log 2 \mathrm{FC}=1.69 ; \mathrm{FDR}=$ 0.0004;). Furthermore, LINC00261 is a tumor suppressor that blocks cellular proliferation by activating the DNA damage response [22].

LINC00303 is expressed upstream of SOX13, a developmental factor expressed in mouse Leydig cells and germ cells [23]. Therefore, this lncRNA could be involved in SOX13 regulation. LINC00293 is expressed upstream of SPIDR, which is involved in doublestranded break repair and genome integrity and binds two TTTY type testis-specific lncRNAs. Several lincRNAs involved in DNA damage repair were increased after GnRHa treatment, including LINC00994 (expressed upstream of PSMD6), LINC00898 (binds mRNA encoding USP1), and testis-specific LINC01553 (interacts with mRNA encoding TIMELESS). TIMELESS plays an important role in the control of DNA replication, the maintenance of genome stability throughout normal DNA replication, and regulation of the circadian clock [24]. (Table 1).

$E G F R-A S 1$, which is involved in determining period length and in the DNA damage-dependent phase advancing the circadian clock [25], interacts with NEU3 mRNA. NEU3 activity enhances EGFR activation without affecting EGFR expression. This may indicate a regulatory mechanism involving a feedback loop. EGFR-AS1 is weakly expressed in adult testis and highly expressed in liver and liver cancer. Intense EGFR immunostaining was found in men with high plasma FSH levels and in all patients who received exogenous FSH, supporting a possible gonadotropin role in the modulation of EGFR expression [25]. GnRHa treatment increased the plasma FSH level and EGFR-AS1, but decreased EGFR expression $(\log 2 \mathrm{FC}=-0.58 ; \mathrm{FDR}=0.01 ;)$. Epidermal growth factor receptor signaling is associated with the pathogenesis of
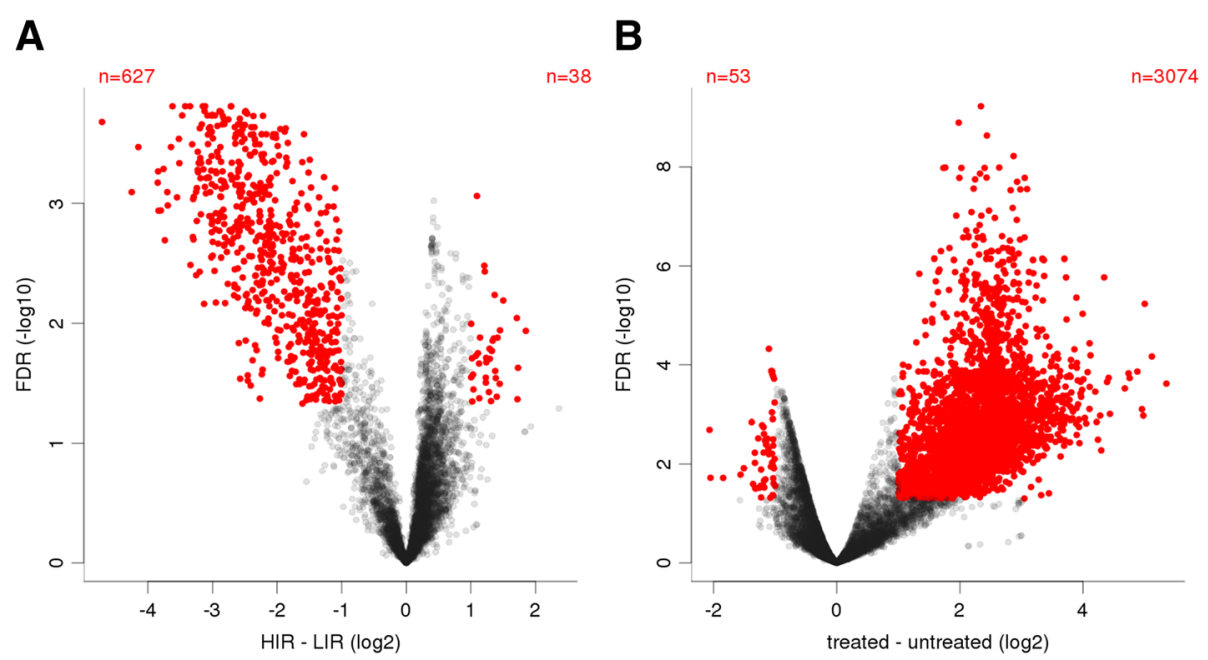

Fig. 3 Volcano plots of IncRNA expression ratios: (a) Between the high (HIR) and low infertility risk (LIR) groups or (b) in the HIR group before and after GnRHa treatment. Genes with no significant difference in expression between the two groups compared in each panel are in black. Differentially expressed genes are shown in red. The most upregulated genes on the right, the most downregulated genes on the left, and the most significant genes at the top 
Table 1 Testicular lincRNAs and AS-IncRNAs that increase after GnRHa treatment and are involved in stem cell renewal and differentiation

\begin{tabular}{|c|c|c|c|c|c|}
\hline Gene ID & $\begin{array}{l}\text { RPKM before GnRHa } \\
\text { Median MAD }\end{array}$ & $\begin{array}{l}\text { RPKM after GnRHa } \\
\text { Median MAD }\end{array}$ & $\log 2 \mathrm{FC}$ GnRH & $p$-value & FDR \\
\hline LINC-ROR & $0.044 / 0.06$ & $0.40 / 0.24$ & 2,68 & 0,0004 & 0,002 \\
\hline LINC00261 & $0.11 / 0.04$ & $1.11 / 0.68$ & 2.60 & 3.588E-08 & 4.35E-06 \\
\hline LINC00293 & $0.05 / 0.04$ & $0.66 / 0.49$ & 2.80 & 0.0001 & 0.001 \\
\hline LINC00303 & $0.22 / 0.07$ & $1.25 / 0.45$ & 2.57 & 0.0001 & 0.0008 \\
\hline LINC00520 & $0.15 / 0.07$ & 0.79 / 0.64 & 2.76 & 0.0002 & 0.001 \\
\hline LINC00898 & $0.04 / 0.03$ & $0.35 / 0.25$ & 2.72 & 0.0002 & 0.001 \\
\hline LINC00974 & $0.07 / 0.04$ & $0.48 / 0.46$ & 3.9 & 0.0008 & 0.003 \\
\hline LINC00994 & $0.20 / 0.10$ & $1.41 / 0.81$ & 2.73 & 5.773E-06 & 0.0001 \\
\hline LINC01016 & $0.15 / 0.03$ & $1.32 / 0.70$ & 3,36 & 2.078E-09 & $6.43 \mathrm{E}-07$ \\
\hline LINC01121 & $0.25 / 0.04$ & $1.84 / 0.45$ & 2.89 & 2.049E-09 & $6.43 \mathrm{E}-07$ \\
\hline LINC01553 & $0.09 / 0.06$ & $1.26 / 0.67$ & 3.60 & 0.0002 & 0.001 \\
\hline EGFR-AS1 & $0.03 / 0.05$ & $0.58 / 0.30$ & 2.99 & 3.850E-07 & $2.28 \mathrm{E}-0.5$ \\
\hline HOTTIP & $0.04 / 0.03$ & $0.47 / 0.37$ & 2.22 & 0.0010 & 0.004 \\
\hline MTOR-ASI & $0.21 / 0.19$ & $1.90 / 1.33$ & 4.96 & $6.67 \mathrm{E}-06$ & 0.0001 \\
\hline OTX2-AS1 & $0.09 / 0.007$ & $0.91 / 0.45$ & 2.37 & 2.95E-0.6 & 8.83E-05 \\
\hline
\end{tabular}

The log-fold changes (FC), p-value, false discovery rate (FDR), median expression values in reads per kilobase per million (RPKM) (Median), and the median absolute deviation (MAD) for LINC samples before and after GnRHa treatment are given

cutaneous squamous cell carcinoma. LINC00520-targeted EGFR inhibition might result in inactivation of the PI3K/ Akt pathway, thereby inhibiting cancer development [26].

HOTTIP mediates the regulation of $C X C L$ genes, which are implicated in Ad spermatogonia differentiation [12]. HOTTIP is antisense to HOXA13 and modulates cancer stem cell properties in human pancreatic cancer by regulating HOXA9 $[27,28]$. OTX2-AS1 is a NAT RNA that plays an important role in eye development and exhibits sequence complementarity to the exon sequences in its corresponding sense gene, OTX2, in both mice and humans [12]. OTX2 is downregulated in $\mathrm{HIR}(\log 2 \mathrm{FC}=-1.73$; $\mathrm{FDR}=0.02$;) and upregulated after $\mathrm{GnRH}$ treatment $(\log 2 \mathrm{FC}=1.24 ; \mathrm{FDR}=0.03)$ [12]. Though no role has been found for OTX2-AS1, deletion of its sense gene OTX1 was found in six patients with genitourinary defects. Three of these individuals were diagnosed with cryptorchidism [29]. MTOR, the key regulator of spermatogenesis [30], is downregulated in boys with HIR $(\log 2 \mathrm{FC}=-0.42 ; \mathrm{FDR}=0.03 ;)$ and remains downregulated after $\mathrm{GnRHa}$ treatment $(\log 2 \mathrm{FC}=-0.53$; FDR $=0.02 ;)$. Its antisense gene, MTOR-AS1, was up-regulated 4.9-log2 by GnRHa treatment (Table 1). Thus far, nothing is known about the function of MTOR-AS1.

LINC-ROR is induced 6.5-fold by GnRHa. (Table 1) This lncRNA controls stem cell renewal and acts as an miRNA sponge via gene silencing, which indicates that the transcript itself has a biological role [31-33]. In addition, we found that BOD1L2, a testis-specific gene, is located downstream of $L I N C-R O R$ and may be transcriptionally regulated by the IncRNA. BOD1L2 plays a role in chromosome biorientation through the detection or correction of syntelic attachments in mitotic spindles [34, 35]. Buserelin treatment increases BOD1L2 gene expression $(\log 2 \mathrm{FC}=$ 1.72 l; FDR = 0.003;), indicating a possible role for it in $\mathrm{Ad}$ spermatogonia differentiation.

\section{LincRNAs downregulated in HIR testes and stimulated after GnRHa treatment are associated with cancer and the transition of ad spermatogonia}

We previously reported different lncRNA expression in patients with HIR compared to LIR; some of these RNAs participate in epigenetic processes, including $A I R N$, ERICH-AS1, FENDRR, HAGLR, and XIST [12]. Here, we focuse on seven lncRNAs with decreased gene expression in HIR, indicating abrogated mini-puberty, and increased expression after GnRHa treatment (Tables 2 and 3).

LINC00922 is expressed upstream of cadherins CDH5 and CDH11; the latter encodes a calciumdependent cell adhesion protein that may play a role in testicular architecture [36].

LINC00221 binds mRNA encoding DCBLD2, which is involved in negative regulation of cell growth. Significant downregulation of DCBLD2 occurred after GnRHa treatment $(\log 2 \mathrm{FC}=-1.0 ; \mathrm{FRD}=0.0002 ;)$. LINC00221 interacts with VPS53's mRNA. The protein acts as component of the GARP complex involved in retrograde transport from early and late endosomes to the trans-Golgi network [37]. 
Table 2 Testicular lincRNAs downregulated in HIR testes compared to LIR

\begin{tabular}{llllll}
\hline lincRNA & LIR & HIR & log2FC & $p$-value & FDR \\
& Median/MAD & Median/ MAD & & & \\
\hline LINC00922 & 0.470 .17 & 0.100 .07 & -1.47 & 0.002 & 0.01 \\
LINC00221 & 0.640 .27 & 0.270 .07 & -1.20 & 0.0007 & 0.008 \\
LINC01249 & 0.430 .28 & 0.150 .08 & -1.42 & 0.001 & 0.01 \\
LINC00701 & 0.290 .03 & 0.110 .06 & -0.84 & 0.002 & 0.02 \\
HOTAIR & 0.490 .23 & 0.130 .09 & -1.74 & 0.0001 & 0.002 \\
DLX6-AS1 & 0.420 .09 & 0.200 .06 & -0.92 & 0.006 & 0.03 \\
LINC01446 & 0.570 .09 & 0.310 .08 & -1.21 & 0.0002 & 0.003 \\
\hline
\end{tabular}

The log-fold changes (FC), $p$-value, false discovery rate (FDR), median expression values in reads per kilobase per million (RPKM) (Median), and the median absolute deviation (MAD) for LINC samples are presented

LINC01249 is expressed upstream of SOX11, which is important for embryonic neurogenesis and tissue modeling. SOX11 is upregulated after GnRHa treatment $(\log 2 \mathrm{FC}=0.7 ; \mathrm{FDR}=0.008)$. It has been suggested that, together with SOX4, SOX11 may function as a transcriptional repressor in fetal testes, contributing to the precise regulation of $S R Y$ and $S O X 9$ [23].

LINC01446 promotes glioblastoma progression by modulating the miR-489-3p/TPT1 pathway [38].

The testis expression of LINC00701 is developmental stage-specific and associated with SLC25A37, encoding a solute carrier localized in the inner mitochondrial membrane. The protein functions as an essential iron importer for the synthesis of mitochondrial heme and ironsulfur clusters [39].

HOX antisense intergenic RNA (HOTAIR) is an lncRNA that coordinates with chromatin-modifying enzymes, regulates gene silencing, and is transcriptionally induced by estradiol (E2) [12, 40, 41].

Distal-less homeobox6 antisense (DLX6-AS1) was downregulated in HIR and responded positively to GnRHa treatment. This supports the observation in mice that DLX6 participates in the control of steroidogenesis [42]. DLX5 and DLX6 showed low or no expression in HIR samples.
TINCR, an lncRNA required for the induction of key differentiation genes, is downregulated in HIR testes $(\log 2 \mathrm{FC}=-1.07 \mathrm{l} ; \mathrm{FDR}=0.002)$. Seven epigenetic modifiers found to bind TINCR were upregulated in HIR and downregulated after GnRHa treatment (Table 4).

\section{Discussion}

In this study, we aimed to gain molecular insight into the effect on testicular lncRNA expression levels of a curative treatment for cryptorchidism and related infertility that combines surgery and nasal administration of GnRHa [11, 12, 14]. We found hundreds of IncRNAs that respond to treatment, including a subset that is present at lower levels in testicular samples from boys with HIR. A detailed interpretation of the expression data revealed candidate lncRNAs that may play important regulatory roles in establishing adult spermatogenesis during early postnatal development in humans. Our data are consistent with the hypothesis that hypogonadotropic hypogonadism in boys with altered minipuberty is the consequence of a profoundly altered gene expression program involving protein-coding genes and lncRNAs. The results point to molecular mechanisms that underlie the ability of GnRHa to rescue fertility.

\section{Study design for human testicular RNA profiling experiments}

When working with human samples, a critical issue is the number of cases included in a given analysis. The number of replicates affects the statistical confidence level, and human tissue samples exhibit intrinsic variability that needs to be controlled. In this exploratory lncRNA profiling study, we included first seven patients chosen sequentially from a study based on randomized patient samples [12, 14]. Their inclusion in the cohorts to be treated or to remain untreated was completely unbiased by any parameter other than undescended testes, which were surgically corrected. This sample size, while small, is enough for an initial transcriptome study as presented here.

Table 3 LncNRAs downregulated in HIR testes and stimulated after GnRHa treatment

\begin{tabular}{lllllc}
\hline lincRNA (RPKM) & $\begin{array}{l}\text { before GnRHa } \\
\text { Median MAD }\end{array}$ & $\begin{array}{l}\text { after GnRHa } \\
\text { Median MAD }\end{array}$ & log2FC & F-value \\
\hline LINC00922 & 0.100 .07 & 0.850 .40 & 1.41 & 0.02 & 0.04 \\
LINC00221 & 0.270 .07 & 1.120 .42 & 1.23 & 0.01 & 0.003 \\
LINC01249 & 0.150 .08 & 0.920 .56 & 1.38 & 0.0009 & 0.01 \\
LINC00701 & 0.110 .06 & 0.720 .48 & 1.28 & 0.01 & 0.003 \\
HOTAIR & 0.130 .09 & 1.040 .87 & 1.14 & $1.55 \mathrm{E}-05$ & 0.03 \\
DLX6-AS1 & 0.200 .06 & 1.130 .81 & 2.02 & 0.0007 & 0.0002 \\
LINC01446 & 0.310 .08 & 1.490 .82 & 1.14 & 003 \\
\hline
\end{tabular}

The log-fold changes (FC), p-value, false discovery rate (FDR), median expression values in reads per kilobase per million (RPKM) (Median), and the median absolute deviation (MAD) for LINC samples before and after GnRHa treatment are shown 
Table 4 Seven epigenetic modifiers that bind TINCR

\begin{tabular}{llllll}
\hline Gene ID & Name & Log2FC HIR/LIR & FDR & $\begin{array}{l}\text { Log2FC } \\
\text { HIR/LIR }\end{array}$ & $\begin{array}{l}\text { FDR } \\
\text { HIR/ GnRHa }\end{array}$ \\
\hline SETD7 & SET domain containing lysine methyltransferase 7 & +0.22 & 0.042 & -0.85 & 0.0006 \\
ARID4B & AT-rich ineraction domain 4B & +0.18 & 0.041 & -0.63 & 0.008 \\
ARID5B & AT-rich interaction domain 5B & +0.35 & 0.004 & -0.49 & 0.003 \\
KDM6A & Iysine demethylase 6A & +0.20 & 0.017 & -0.81 & 0.0009 \\
CHD6 & chromodomain helicase DNA binding protein 6 & +0.21 & 0.040 & -0.54 & 0.03 \\
MBD2 & methyl-CpG binding domain protein 2 & +0.23 & 0.029 & -0.68 & 0.004 \\
BPTF & bromodomain PHD finger transcription factor & +0.19 & 0.055 & -0.61 & 0.01 \\
\hline
\end{tabular}

The log-fold changes (FC), p-value, false discovery rate (FDR), comparing HIR and LIR cryptorchid testes as well as results from HIR group following GnRHa treatment are presented

Curative hormone treatment affects signaling pathways During GnRHa treatment, increased LH and testosterone secretion induced the transition of gonocytes and undifferentiated spermatogonia into Ad spermatogonia. In this context, it is interesting that the expression of LINC-ROR, a key regulator of pluripotent stem cell reprogramming, increased after hormone treatment. LINC-ROR influences cell differentiation, in part, by acting as a sponge for miR-138 and miR-145 and by activating both the canonical and non-canonical WNT/ $\beta$-catenin signaling pathways [31]. Importantly, an increase in $m T O R-A S 1$ expression after GnRHa treatment may have resulted in the suppression of $m T O R$ activity, allowing spermatogonial stem cells to undergo selfrenewal. WNT3 induces many transcription factors associated with mesoderm and is downregulated in the testes of men with HIR testes [12]. WNT interacts with mTOR signaling to affect cancer cell growth and tumor metabolism [43], as well as the formation of spermatozoa [30]. We propose that WNT3 is the signaling component that regulates early expression of Brachyury (T) [44], a mesodermal factor known to determine the fate of Ad spermatogonia. $\mathrm{T}$ is a classical and conserved mesodermal factor essential for robust activation of the germline determinants PRDM1 and PRDM14 [45]. T directly upregulates these genes, thereby delineating the downstream primordial germ cell program. In mutant mice lacking Bmp4, a program induced by WNT3 prevents $\mathrm{T}$ from activating PRDM1 and PRDM14, demonstrating a permissive role of $B m p 4$ in primordial gem cell specification [45]. We found that DMRTC2, PAX7, T, and TERT are downregulated in testes with defective mini-puberty and respond to GnRHa treatment [46]. Furthermore, we found lower levels of PRDM1, PRDM6, PRDM9, PRDM13, and PRDM14 mRNA in the testes of patients with HIR compared to LIR, and PRDM7, PRDM9, $P R D M 12$, and PRDM16 were significantly induced after GnRHa treatment. Thus, GnRHa treatment induces an alternate pathway to stimulate PRDM9 for Ad spermatogonia specification without the permissive role of $B M P 4$, but increased the expression of $B M P 5 \quad(\log 2 \mathrm{FC}=2.31$; $\mathrm{FDR}=0.0001$;) [12, 47]. LINC01121 is expressed upstream of SIX2 and may therefore influence its expression. SIX2 and WNT regulate the self-renewal and commitment of nephron progenitors through shared gene regulatory networks [16-18]. SIX2 also activates the expression of GDNF and plays a role in cell proliferation and migration. Testes in men with HIR expressed lower levels of SIX2 than LIR testes $(\log 2 \mathrm{FC}=-1.76 ; \mathrm{FDR}=0.0008)$. GnRHa treatment increased $S I X 2(\log 2 \mathrm{FC}=1.61 ; \mathrm{FDR}=0.014)$ and $G D N F$ $(\log 2 \mathrm{FC}=1.46 ; \mathrm{FDR}=0.003)$ expression. Taken together, our results support the notion that LINC-ROR and $m T O R$ are involved in Ad spermatogonia development and specification via the WNT signaling pathway.

\section{Hormone treatment influences epigenetic factors}

LINC00261 stimulates the expression of HOTAIR and HOTTIP genes to stabilize androgen receptor (AR) together with FOXA1. Specifically, the DNA-binding domain (DBD)/hinge region of AR directly interacts with the fork head domain of FOXA1, thereby acting as an AR-collaborating factor [48].

HOTAIR's promoter contains multiple functional estrogen response elements (EREs). HOTAIR mediates the recruitment of H3K27 methyltransferase and H3K4 demethylase, which leads to efficient repression of certain loci. The levels of histone $\mathrm{H} 3$ lysine-4 trimethylation, histone acetylation, and RNA polymerase II recruitment are increased at the HOTAIR promoter in the presence of E2, and knock-down of ERs downregulated E2-induced HOTAIR expression. Thus, like the transcription of protein-coding genes, E2 induces the transcription of antisense RNAs [27, 49, 50]. HIR patient's exhibit decreased HOTAIR levels, [12] and GnRHa treatment induced HOTAIR expression, indicating that $\mathrm{LH}$, testosterone and/or converted E2 have a positive effect on HOTAIR and, thus, Ad spermatogonia differentiation [12]. Furthermore, HOTAIR was previously shown to mediate tumorigenesis by recruiting EZH2 [51]. This is of interest, as GnRHa induces expression of HOTAIR, downregulates EZH2 $(\log 2 \mathrm{FC}=-0.6 ; \mathrm{FDR}=0.01)$ and 
implicates the regulation of HOTTIP gene transcription, which then transcriptionally regulates the HOXA cluster. As a result, an increase occurs in HOXA2 $(\log 2 \mathrm{FC}=2.38 ; \quad \mathrm{FDR}=0.007)$, HOXA3 $(\log 2 \mathrm{FC}=1.68 ;$ $\mathrm{FDR}=0.007), H O X A 11(\log 2 \mathrm{FC}=1.77 ; \mathrm{FDR}=0.02)$, and HOXA-AS3 $(\log 2 \mathrm{FC}=2.68 ; \mathrm{FDR}=0.0001)$.

Gamma-aminobutyric acid (GABA) plays a key developmental role in the regulation of $\mathrm{GnRH}$ neuron migration from the olfactory placodes into the forebrain during fetal development [52], and co-expression of $D L X 3$ and PAX6 proteins, correlates with acquisition of the olfactory placode fate [53]. Moreover, GABA-A receptors and GABA transporter 1 (GAT1) have been reported to be involved in the proliferation of Leydig cells, testosterone production, and spermatogenesis [54]. GABRA $3(\log 2 \mathrm{FC}=-2.49 ; \mathrm{FDR}=0.0001 ;)$ and GABR5 $(\log 2 \mathrm{FC}=-2.59 ; \mathrm{FDR}=0.0006 ;)$ were downregulated in HIR testes. Following GnRHa treatment, an increase expression was observed in DLX3, PAX6 [12], and TP63 $(\log 2 \mathrm{FC}=0.91 ; \mathrm{FDR}=0.002 ;)$, whereby the latter was downregulated in HIR $(\log 2 \mathrm{FC}=-1.58 ; \mathrm{FDR}=0.001 ;)$. Berghoff et al. proposed a model in which DLX6-AS1 inhibits the ultraconserved DNA methylation mark in $D L X 5 / 6$, facilitating antagonistic interactions between repressive and activating transcription factors $M E C P 2$ and $D L X$ [53]. $D L X 2, D L X 3, D L X 5$ and $D L X 6$ showed low or no expression in HIR samples [12] Loss of $D L X 1 / 2$ increases site-specific methylation of the $D L X 5 / 6$ ultraconserved enhancer [53]. Tp63 regulates DLX5 and $D L X 6$ transcription, at least in part, via cis-acting regulation at the promoter level [55]. These interactions allow differential control of adjacent genes by shared DNA regulatory elements [56]. It was also shown that deletion of Dlx5 and Dlx6 in the mouse leads to decreased testosterone levels and an abnormal masculinization phenotype [42]. Thus, impaired steroidogenesis during minipuberty in HIR boys may be induced by altered GABRA-A receptor signaling, silenced $D L X 6$ expression as well as destabilization of AR and ERs.

\section{GnRHa treatment affects genes associated with normal and pathological cell division}

Several recent studies have reported roles for IncRNAs in cancer, including MALAT1 and GAS, strongly indicating that lncRNAs not only control gene regulatory pathways in normal cells and tissue, but also during tumor development $[57,58]$. The occurrence and progression of cancer is the result of a combination of multiple factors. Furthermore, cancer-specific lncRNA expression patterns appear to be more tissue- and stage-specific than those of protein-coding genes, supporting the potential development of lncRNAs as efficient biomarkers and therapeutic targets [58]. Interestingly, GnRHa treatment increased $\mathrm{LH}$ and testosterone secretion and
HOTAIR expression, and probably its recruitment to chromatin, whereas the expression of MALAT1 was reduced $(\log 2 \mathrm{FC}=-0.64 ; \mathrm{FDR}=0.03 ; \mathrm{REF})$, suggesting opposite regulation and functions of these lncRNAs during normal testis development. It was reported that LINC-ROR promote liver cancer stem cell growth by upregulating TERT and C-MYC [59]. Notably, GnRHa treatment stimulates the expression of TERT $(\log 2 \mathrm{FC}=$ 0.91; $\mathrm{FDR}=0.002 ;$ ) [46], which is decreased in HIR $(\log 2 \mathrm{FC}=-1.58 ; \mathrm{FDR}=0.001 ;)$ [46] but downregulates $C-M Y C$ signaling $(\log 2 \mathrm{FC}=-0.58 ; \mathrm{FDR}=0.01 ;)$.

Variation in lincRNA expression may be associated with cancer progression. For example, LINC00261, which plays an important role in gastric cancer, is stimulated by GnRHa, and exerts tumor suppressive activity by reducing cancer cell invasion via suppression of the epithelialmesenchymal transition process [60]. Another lincRNA, TINCR, is involved in normal tissue differentiation and plays a critical role in cancer and metastasis. TINCR expression is downregulated in HIR $(\log 2 \mathrm{FC}=-1.07 ; \mathrm{FDR}=$ 0.002;) [12]. We observed that TINCR depletion in HIR testes resulted in the induction of key epigenetic modifiers, seven of which were downregulated following GnRHa treatment (Table 4). One of them, SETD7, is an epigenetic modifier and regulates AR [61]. SETD7 binds TINCR and may mediate the formation of AR-associated coactivator complexes. Taken together, the results indicate that the HIR group of cryptorchid boys with abortive mini-puberty expresses several cancer genes. Gonadotropin-releasing hormone treatment may protect against testicular tumor development by downregulating oncogenes, such as MALAT1, mTOR, C-MYC, and EZH2 to enable normal germ cell development.

\section{Conclusions}

Two major goals in the field of male reproductive biology are to elucidate the molecular mechanisms that underlie cryptorchidism and to develop an effective treatment for its long-term consequences. According to the mini-puberty hypothesis, early-life exposure to gonadal hormones during a specific window of sensitivity triggers sex-specific developmental processes. To preserve molecular features of differentiated cells, it is crucial that transcriptional alterations triggered by external or intrinsic signals continue beyond the initial stimulus. One possible mechanism involves epigenetic histone variant replacement, chromatin remodeling factors, and lncRNAs associated with epigenetic factors. We found that many of the lincRNAs responding to GnRHa treatment are associated with somatic cancer. This may reflect the fact that the hormone stimulates germ stem cell growth and Leydig, as well as Sertoli, cell division. The mechanisms involved are likely rather diverse and may include promoter/enhancer activity, miRNA sponge 
activity, or control of gene expression via RNA-RNA interactions. We propose that the lncRNAs identified in this study may be involved in establishing normal male fertility by acting at early stages of spermatogonia stem cell development and by affecting other testicular cells capable of responding to GnRHa treatment. Our results provide information's for further functional analysis of long-noncoding RNA in relation to the infertility development. We propose that the HOTAIR and DLX pathways, as well as both canonical and non-canonical WNT pathways, are involved in Ad spermatogonia growth and differentiation.

\section{Abbreviations}

1PRDM6: PR/SET domain 6; AIRN: Antisense of IGF2R (insulin like growth factor 2 receptor) non-protein coding RNA; AR: Androgen receptor; ARID4B: AT-rich interaction domain 4B; ARID5B: AT-rich interaction domain 5B; AS-IncRNA: Antisense long non-coding RNA; Bmp4: Bone morphogenetic protein 4; BMP5: Bone morphogenetic protein 5; BOD1L2: Biorientation of chromosomes in cell division 1 like 2; BPTF: Bromodomain PHD finger transcription factor; $\mathrm{CDH} 11$ : Cadherin 11; $\mathrm{CDH} 5$ : Cadherin 5; CDH6: Cadherin 6; C-MYC: v-myc avian myelocytomatosis viral oncogene homolog; CXCL: Chemokine; DBD: DNA-binding domain; dbGaP: Database of Genotypes and Phenotypes; DCBLD2: Discoidin, CUB and LCCL domain containing 2; DLX: Distal-less homeobox; DLX2: Distal-less homeobox 2 [Homo sapiens (human)]; DLX3: Distal-less homeobox 3 [Homo sapiens (human)]; Dlx5: Distal-less homeobox 5 [Mus musculus (house mouse)]; Dlx6: Distal-less homeobox 6 [Mus musculus (house mouse)]; DLX6AS1: Distal-less homeobox 6 antisense RNA 1; DMRTC2: DMRT (doublesex and mab-3 related transcription factor) like family C2; E2: Estradiol; EGFR: Epidermal growth factor receptor; EGFR-AS1: Epidermal growth factor receptor antisense RNA 1; EREs: Estrogen response elements; ERICHAS1: Glutamate rich protein antisense RNA 1; ERs: Estrogen receptors; ESC: Embryonic stem-cell; EZH2: Enhancer of zeste 2 polycomb repressive complex 2 subunit; FDR: False discovery rate; FENDRR: FOXF1 (forkhead box F1) adjacent non-coding developmental regulatory RNA; FOXA1: Forkhead box A1; FOXA2: Forkhead box A2; FSH: Follicle stimulating hormone; GABA: Gamma-aminobutyric acid; GABA-A: Gamma-aminobutyric acid type A; GABRA-A: gamma-aminobutyric acid (GABA) A receptor, alpha 1; GABRAA5: Gamma-aminobutyric acid (GABRA) A receptor 5; GARP: Golgi-associated retrograde protein; GAS: Growth arrest specific; GAT1: GABA (gammaaminobutyric acid) transporter 1; GDNF: Glial cell derived neurotrophic factor; GnRHa: Gonadotropin releasing hormone antagonist; H3K27: Histone H3 Lysine 27; H3K4: Histone H3 Lysine 4; HAGLR: HOXD (homeobox D cluster) antisense growth-associated long non-coding RNA; HIR: High infertility risk; HOTAIR: HOX (homeobox) transcript antisense RNA; HOTTIP: HOXA (homeobox A cluster) distal transcript antisense RNA; HOXA11: Homeobox A11; HOXA13: Homeobox A13; HOXA2: Homeobox A2; HOXA3: Homeobox A3; HOXA9: Homeobox A9; HOXA-AS3: HOXA (Homeobox A) cluster antisense RNA 3; KDM6A: Lysine demethylase 6A; LH: Luteinizing hormone; LINC00221: Long intergenic non-protein coding RNA 221; LINC00261: Long intergenic non-protein coding RNA 261; LINC00282: long intergenic nonprotein coding RNA 282; LINC00293: Long intergenic non-protein coding RNA 293; LINC00303: Long intergenic non-protein coding RNA 303; LINC00520: Long intergenic non-protein coding RNA 520; LINC00701: Long intergenic non-protein coding RNA 701; LINC00898: Long intergenic nonprotein coding RNA 898; LINC00922: Long intergenic non-protein coding RNA 922; LINC00974: Long intergenic non-protein coding RNA 974; LINC00994: Long intergenic non-protein coding RNA 994; LINC01016: Long intergenic non-protein coding RNA 1016; LINC01121: Long intergenic nonprotein coding RNA 1121; LINC01249: Long intergenic non-protein coding RNA 1249; LINC01446: Long intergenic non-protein coding RNA 1446; LINC01553: Long intergenic non-protein coding RNA 1553; lincRNA: Long intergenic non-protein coding RNA; Linc-ROR: Long intergenic non-protein coding RNA, regulator of reprogramming; LIR: Low infertility risk; IncRNA: Long non-coding RNA; log2FC: log2 fold change; MALAT1: Metastasis associated lung adenocarcinoma transcript 1; MBD2: Methyl-CpG binding domain protein 2; MECP2: methyl-CpG binding protein 2; miR-138: microRNA 138; miR-145: microRNA 1; miR-4893P: microRNA 489; MLN: Motilin; MTOR: mechanistic target of rapamycin kinase; MTOR-AS1: MTOR (mechanistic target of rapamycin kinase) antisense RNA 1; NAT RNA: N-acetyltransferase RNA; NATs: Natural antisense transcripts; NEU3: Neuraminidase 3; OSR1: Odd-skipped related transcription factor 1; OTX1: Orthodenticle homeobox 1; OTX2: Orthodenticle homeobox 2; OTX2AS1: Orthodenticle homeobox 2 antisense RNA 1 (head to head); PAX1: Paired box 1; PAX6: Paired box 6; PAX7: Paired box 7; PI3K/Akt pathway: Phosphatidylinositol 3-kinase, putative, and protein kinase B pathway; PRDM1: PR domain containing 1, with ZNF domain; PRDM12: PR/ SET domain 12; PRDM14: PR/SET domain 14; PRDM16: PR/SET domain 16; PRDM7: PR/SET domain 7; PRDM9: PR/SET domain 9; PRMD13: PR/SET domain 13; PSMD6: Proteasome 265 subunit, non-ATPase (adenosine triphosphatase) 6; RPKM: Reads per kilo base per million mapped reads; S/ T: Total germ cell count per tubule; SETD7: SET domain containing 7, histone lysine methyltransferase; SIX2: SIX homeobox 2; SLC25A37: Solute carrier family 25 member 37; SOX11: SRY (sex determining region Y)-box transcription factor 11; SOX13: SRY (sex determining region Y)-box transcription factor 13; SOX4: SRY (sex determining region Y)-box transcription factor 4; SPIDR: Scaffold protein involved in DNA repair; SRY: Sex determining region of Y; T: Brachyury; TCF7L2: Transcription factor 7 like 2; TERT: Telomerase reverse transcriptase; TIMELESS: Timeless circadian regulator; TINCR: TINCR (Tissue differentiation-inducing non-protein coding RNA) ubiquitin domain containing; TP63: Tumor protein p63; TPT1: Tumor protein, translationally-controlled 1; TTT: Testis-specific transcript, Y-linked; USP1: Ubiquitin specific peptidase 1; VPS53: VPS53 (Vacuolar protein sorting 53 homolog) subunit of GARP (Golgi-associated retrograde protein) complex; Wnt: Wingless-related integration site; WNT3: Wnt family member 3; WNT4: Wnt family member 4; XIST: Inactive $X$ specific transcripts

\section{Acknowledgments}

We thank Manuel Kohler, Department of Biosystems Science and Engineering (D-BSSE), ETH Zurich, for helping us perform the RNA sequencing.

\section{Authors' contributions}

FH conceived and designed the study, interpreted the data, and organized and wrote the manuscript. GV performed experiments, analyzed the data, and read the paper. BV performed experiments and read the paper. MBS analyzed and interpreted the data, contributed analysis tools, and read the paper.

\section{Funding}

This study was supported in part by the European Social Fund under the Global Grant measure. Work in the Stadler group is supported by funding from the MetastasiX project of SystemsX.ch.

\section{Availability of data and materials}

Raw data files were deposited at the Database of Genotypes and Phenotypes (dbGaP) under accession number phs001275.v1.p1.

\section{Ethics approval and consent to participate}

Investigations were carried out in accordance with the Declaration of Helsinki of 1975 (revised in 2008). The study was approved by the Institutional Review Board and the Independent Ethics Committee of Vilnius University (Vilnius Regional Biomedical Research Ethics Committee, No. 158200-580-PPI-17, 11 June 2013).

\section{Consent for publication}

Written informed consent was obtained from the patients' guardians after approval by the ethical committee.

\section{Competing interests}

The authors declare no conflicts of interest.

\section{Author details}

${ }^{1}$ Cryptorchidism Research Institute, Children's Day Care Center, 4410 Liestal, Switzerland. ${ }^{2}$ Children's Surgery Centre, Faculty of Medicine, Vilnius University, 01513 Vilnius, Lithuania. ${ }^{3}$ Children's Surgery Centre, Clinic of Gastroenterology, Nephrourology and Surgery, Institute of Clinical Medicine, Faculty of Medicine, Vilnius University, Vilnius, Lithuania. ${ }^{4}$ Friedrich Miescher 
Institute for Biomedical Research, Basel, Switzerland. ${ }^{5}$ Swiss Institute of Bioinformatics, Basel, Switzerland.

\section{Received: 21 August 2019 Accepted: 10 December 2019} Published online: 27 December 2019

\section{References}

1. Wang KC, Chang HY. Molecular mechanisms of long noncoding RNAs. Mo Cell. 2011:43:904-14.

2. Pelechano $V$, Steinmetz LM. Gene regulation by antisense transcription. Nat Rev Genet. 2013:14:880-93.

3. Tufarelli C, Stanley JA, Garrick D, Sharpe JA, Ayyub H, Wood WG, et al. Transcription of antisense RNA leading to gene silencing and methylation as a novel cause of human genetic disease. Nat Genet. 2003;34:157-65.

4. Fernandes JCR, Acuña SM, Aoki Jl, Floeter-Winter LM, Muxel SM. Long noncoding RNAs in the regulation of gene expression: physiology and disease. Noncoding RNA. 2019;5(1):17. https://doi.org/10.3390/ncrna50100175.

5. Hadjicharalambous MR, Lindsay MA. Long non-coding RNAs and the innate immune response. Noncoding RNA. 2019;5(2):34. https://doi.org/10.3390/ ncrna5020034.

6. Carninci P, Kasukawa T, Katayama S, Gough J, Frith MC, Maeda N, et al. The transcriptional landscape of the mammalian genome. Science. 2005;309: 1559-63.

7. Djebali S, Davis CA, Merkel A, Dobin A, Lassmann T, Mortazavi A, et al. Landscape of transcription in human cells. Nature. 2012;489:101-8.

8. Forrest AR, Kawaji H, Rehli M, Baillie JK, de Hoon MJ, Haberle V, et al. FANTOM consortium and the RIKEN PMI and CLST (DGT): a promoter-level mammalian expression atlas. Nature. 2014;507:462-70.

9. Hadziselimovic F, Herzog B. The importance of both an early orchidopexy and germ cell maturation for fertility. Lancet. 2001:358:1156-7.

10. Hadziselimovic F, Hocht B, Herzog B, Buser MW. Infertility in cryptorchidism is linked to the stage of germ cell development at orchidopexy. Horm Res. 2007;68:46-52.

11. Hadziselimovic F. Successful treatment of unilateral cryptorchid boys risking infertility with LH-RH analogue. Int Braz J Urol. 2008;34:319-26.

12. Hadziselimovic F, Gegenschatz-Schmid K, Verkauskas G, Demougin P, Bilius $V$, Dasevicius D, et al. GnRHa treatment of Cryptorchid boys affects genes involved in hormonal control of the HPG Axis and fertility. Sex Dev. 2017; 11(3):126-36.

13. Verkauskas G, Malcius D, Eidukaite A, Vilimas J, Dasevicius D, Bilius V, et al. Prospective study of histological and endocrine parameters of gonadal function in boys with cryptorchidism. J Pediatr Urol. 2016;12(4):238.e1-6. https://doi.org/10.1016/j.jpurol.2016.05.007.

14. Vincel B, Verkauskas G, Bilius V, Dasevicius D, Malcius D, Jones B, et al. Gonadotropin-releasing hormone agonist corrects defective mini-puberty in boys with cryptorchidism: a prospective randomized study. Biomed Res Int. 2018. https://doi.org/10.1155/2018/4651218.

15. Jonsson P, Coarfa C, Mesmar F, Raz T, Rajapakshe K, Thompson JF, et al. Single-molecule sequencing reveals estrogen-regulated clinically relevant IncRNAs in breast Cancer. Mol Endocrinol. 2015;29(11):1634-45. https://doi. org/10.1210/me.2015-1153

16. Park JS, Ma W, O'Brien LL, Chung E, Guo JJ, Cheng JG, et al. Six2 and Wnt regulate self-renewal and commitment of nephron progenitors through shared gene regulatory networks. Dev Cell. 2012;23(3):637-51.

17. Liu H, Chen S, Yao X, Li Y, Chen CH, Liu J, et al. Histone deacetylases 1 and 2 regulate the transcriptional programs of nephron progenitors and renal vesicles. Development. 2018. https://doi.org/10.1242/dev.153619.

18. Xu Xu J, Liu H, Park JS, Lan Y, Jiang R. Osr1 acts downstream of and interacts synergistically with Six2 to maintain nephron progenitor cells during kidney organogenesis. Development. 2014;141(7):1442-52. https:// doi.org/10.1242/dev.103283.

19. Fang Q, Sang L, Du S. Long noncoding RNA LINC00261 regulates endometrial carcinoma progression by modulating miRNA/FOXO1 expression. Cell Biochem Funct. 2018;36(6):323-30. https://doi.org/10. 1002/cbf.3352

20. Liu Z, Dai J, Shen H. Systematic analysis reveals long noncoding RNAs regulating neighboring transcription factors in human cancers. Biochim Biophys Acta Mol basis Dis. 2018;1864(9 Pt B):2785-92.

21. Connelly ZM, Yang S, Chen F, Yeh Y, Khater N, Jin R, et al. Foxa2 activates the transcription of androgen receptor target genes in castrate resistant prostatic tumors. Am J Clin Exp Urol. 2018;6(5):172-81.
22. Shahabi S, Kumaran V, Castillo J, Cong Z, Nandagopal G, Mullen DJ, et al. LINC00261 is an epigenetically regulated tumor suppressor essential for activation of the DNA damage response. Cancer Res. 2019;79(12):3050-62. https://doi.org/10.1158/0008-5472.CAN-18-2034.

23. Daigle M, Roumaud P, Martin LJ. Expressions of Sox9, Sox5, and Sox13 transcription factors in mice testis during postnatal development. Mol Cell Biochem. 2015;407:209-21.

24. Shen X, Li M, Mao Z, Yu W. Loss of circadian protein TIMELESS accelerates the progression of cellular senescence. Biochem Biophys Res Commun. 2018;503(4):2784-91. https://doi.org/10.1016/j.bbrc.2018.08.040.

25. Foresta C, Varotto A. Immunocytochemical localization of epidermal growth factor receptors in human testis from infertile subjects. Fertil Steril. 1994; 61(5):941-8.

26. Mei XL, Zhong S. Long noncoding RNA LINC00520 prevents the progression of cutaneous squamous cell carcinoma through the inactivation of the PI3K Akt signaling pathway by downregulating EGFR. Chin Med J. 2019;132(4):454-65.

27. Lin C, Wang Y, Wang Y, Zhang S, Yu L, Guo C, et al. Transcriptional and posttranscriptional regulation of HOXA13 by IncRNA HOTTIP facilitates tumorigenesis and metastasis in esophageal squamous carcinoma cells. Oncogene. 2017:36(38):5392-406. https://doi.org/10.1038/onc.2017.133.

28. Cheng Y, Jutooru I, Chadalapaka G, Corton JC, Safe S. The long noncoding RNA HOTTIP enhances pancreatic cancer cell proliferation, survival and migration. Oncotarget. 2015;6(13):10840-52.

29. Jorgez CJ, Rosenfeld JA, Wilken NR, Vangapandu HV, Sahin A, Pham $D$, et al. Genitourinary defects associated with genomic deletions in 2p15 encompassing OTX1. PLoS One. 2014. https://doi.org/10.1371/ journal.pone.0107028.

30. Xu H, Shen L, Chen X, Ding Y, He J, Zhu J, et al. mTOR/P70S6K promotes spermatogonia proliferation and spermatogenesis in Sprague Dawley rats. Reprod BioMed Online. 2016;32(2):207-17.

31. Loewer S, Cabili MN, Guttman M, Loh YH, Thomas K, Park IH, et al. Large intergenic non-coding RNA-RoR modulates reprogramming of human induced pluripotent stem cells. Nat Genet. 2010;42(12):1113-7.

32. Wang $Y, X u$ Z, Jiang J, Xu C, Kang J, Xiao L, et al. Endogenous miRNA sponge lincRNA-RoR regulates Oct4, Nanog, and Sox2 in human embryonic stem. Dev Cell. 2013;25(1):69-80.

33. Zou G, Liu T, Guo L, Huang Y, Feng Y, Huang Q, et al. miR-145 modulates IncRNA-ROR and Sox2 expression to maintain human amniotic epithelial stem cell pluripotency and $\beta$ islet-like cell differentiation efficiency. Gene. 2016;591(1):48-57

34. Porter IM, McClelland SE, Khoudoli GA, Hunter CJ, Andersen JS, McAinsh AD et al. Bod1, a novel kinetochore protein required for chromosome biorientation. J Cell Biol. 2007;179(2):187-97.

35. Cleveland DW, Mao Y, Sullivan KF. Centromere and kinetochores: from epigenetics to mitotic checkpoint signaling. Cell. 2003;112(4):407-21.

36. Hawi Z, Tong J, Dark C, Yates H, Johnson B, Bellgrove MA. The role of cadherin genes in five major psychiatric disorders: a literature update. Am J Med Genet. 2018;177(2):168-80. https://doi.org/10.1002/ajmg.b.32592.

37. Liewen $H$, Meinhold-Heerlein I, Oliveira V, Schwarzenbacher R, Luo G, Wadle A, et al. Characterization of the human GARP (Golgi associated retrograde protein) complex. Exp Cell Res. 2005;306(1):24-34.

38. Zhang $L$, Wang $Q$, Wang $F$, Zhang $X$, Zhang $L$, Tang $Y$, et al. LncRNA LINC01446 promotes glioblastoma progression by modulating miR-489-3p/ TPT1 axis. Biochem Biophys Res Commun. 2018:503(3):1484-90.

39. Chen W, Paradkar PN, Li L, Pierce EL, Langer NB, Takahashi-Makise N, et al. Abcb10 physically interacts with mitoferrin-1 (SIc25a37) to enhance its stability and function in the erythroid mitochondria. Proc Natl Acad Sci U S A. 2009;106(38):16263-8.

40. Bhan A, Mandal SS. LncRNA HOTAIR: a master regulator of chromatin dynamics and cancer. Biochim Biophys Acta. 2015;1856(1):151-64.

41. Bhan A, Mandal SS. Estradiol-induced transcriptional regulation of long noncoding RNA, HOTAIR. Methods Mol Biol. 2016;1366:395-412.

42. Nishida H, Miyagawa S, Vieux-Rochas M, Morini M, Ogino Y, Suzuki K, et al. Positive regulation of steroidogenic acute regulatory protein gene expression through the interaction between Dlx and GATA-4 for testicular steroidogenesis. Endocrinology. 2008;149(5):2090-7.

43. Zeng H, Lu B, Zamponi R, Yang Z, Wetzel K, Loureiro J, et al. mTORC1 signaling suppresses Wnt/ $\beta$-catenin signaling through DVL-dependent regulation of Wht receptor FZD level. Proc Natl Acad Sci U S A. 2018; 115(44):E10362-9. https://doi.org/10.1073/pnas.1808575115. 
44. Di Ruscio A, Ebralidze AK, Benoukraf T, Amabile G, Goff LA, Terragni J, et al. DNMT1-interacting RNAs block gene-specific DNA methylation. Nature. 2013;503:371-6.

45. Aramaki S, Hayashi K, Kurimoto K, Ohta H, Yabuta Y, Iwanari H, et al. A mesodermal factor, $T$, specifies mouse germ cell fate by directly activating germline determinants. Dev Cell. 2013;27(5):516-29. https://doi.org/10.1016/ j.devcel.2013.11.001

46. Gegenschatz-Schmid K, Verkauskas G, Demougin P, Bilius V, Dasevicius D, Stadler MB, et al. DMRTC2, PAX7, BRACHYURY/T and TERT are implicated in male germ cell development following curative hormone treatment for cryptorchidism-induced infertility. Genes (Basel). 2017. https://doi.org/10. 3390/genes8100267.

47. Hadziselimovic F, Cathomas G, Verkauskas G, Dasevicius D, Stadler MB. PRDM histone methyltransferase mRNA levels increase in response to curative hormone treatment for cryptorchidism-dependent male infertility. Genes (Basel). 2018. https://doi.org/10.3390/genes9080391.

48. Gao N, Zhang J, Rao MA, Case TC, Mirosevich J, Wang Y, et al. The role of hepatocyte nuclear factor-3 alpha (Forkhead Box A1) and androgen receptor in transcriptional regulation of prostatic genes. Mol Endocrinol. 2003;17(8):1484-507.

49. Huang KB, Zhang SP, Zhu YJ, Guo CH, Yang M, Liu J, et al. Hotair mediates tumorigenesis through recruiting EZH2 in colorectal cancer. J Cell Biochem. 2019;120(4):6071-7.

50. Aiello A, Bacci L, Re A, Ripoli C, Pierconti F, Pinto F, et al. MALAT1 and HOTAIR long non-coding RNAs play opposite role in estrogen-mediated transcriptional regulation in prostate cancer cells. Sci Rep. 2016;6:38414. https://doi.org/10.1038/srep38414.

51. Cheng Y, Jutooru I, Chadalapaka G, Corton JC, Safe S. The long non-coding RNA HOTTIP enhances pancreatic cancer cell proliferation, survival and migration. Oncotarget. 2015;6(13):10840-52.

52. Watanabe M, Fukuda A, Nabekura J. The role of GABA in the regulation of GnRH neurons. Front Neurosci. 2014;8:38. https://doi.org/10.3389/fnins.2014. 00387.

53. Berghoff EG, Clark MF, Chen S, Cajigas I, Leib DE, Kohtz JD. Evf2 (Dlx6as) IncRNA regulates ultraconserved enhancer methylation and the differential transcriptional control of adjacent genes. Development. 2013;140(21):440716. https://doi.org/10.1242/dev.099390.

54. Kaewman P, Nudmamud-Thanoi S, Thanoi S. GABAergic alterations in the rat testis after methamphetamine exposure. Int J Med Sci. 2018;15:1349-54.

55. Lo lacono N, Mantero S, Chiarelli A, Garcia E, Mills AA, Morasso Ml, et al. Regulation of D1x5 and Dlx6 gene expression by p63 is involved in EEC and SHFM congenital limb defects. Development. 2008;135(7):1377-88.

56. Bhattacharyya S, Bronner-Fraser M. Competence, specification and commitment to an olfactory placode fate. Development. 2008;135(24):4165-77.

57. Ji Q, Liu X, Fu X, Zhang L, Sui H, Zhou L, et al. Resveratrol inhibits invasion and metastasis of colorectal cancer cells via MALAT1 mediated Wnt/ $\beta$ catenin signal pathway. PLoS One. 2013. https://doi.org/10.1371/journal. pone.0078700

58. Wang J, Zhang X, Chen W, Hu X, Li J, Liu C. Regulatory roles of long noncoding RNAs implicated in cancer hallmarks. Int J Cancer. 2019. https:// doi.org/10.1002/ijc.32277.

59. Pu H, Zheng Q, Li H, Wu M, An J, Gui X, et al. CUDR promotes liver cancer stem cell growth through upregulating TERT and C- Myc. Oncotarget. 2015; 6(38):40775-98.

60. Ye Y, Li L, Zheng Z, Chen S, Chen E, Hu Y. Long non-coding RNA linc0026 suppress gastric cancer progression via promoting slug degradation. J Cell Mol Med. 2017;21(5):955-67.

61. Ko S, Ahn J, Song CS, Kim S, Knapczyk-Stwora K, Chatterjee B. Lysine methylation and functional modulation of androgen receptor by Set9 methyltransferase. Mol Endocrinol. 2011;25(3):433-44. https://doi.org/10. 1210/me.2010-0482.

\section{Publisher's Note}

Springer Nature remains neutral with regard to jurisdictional claims in published maps and institutional affiliations.

Ready to submit your research? Choose BMC and benefit from:

- fast, convenient online submission

- thorough peer review by experienced researchers in your field

- rapid publication on acceptance

- support for research data, including large and complex data types

- gold Open Access which fosters wider collaboration and increased citations

- maximum visibility for your research: over $100 \mathrm{M}$ website views per year

At BMC, research is always in progress.

Learn more biomedcentral.com/submissions 